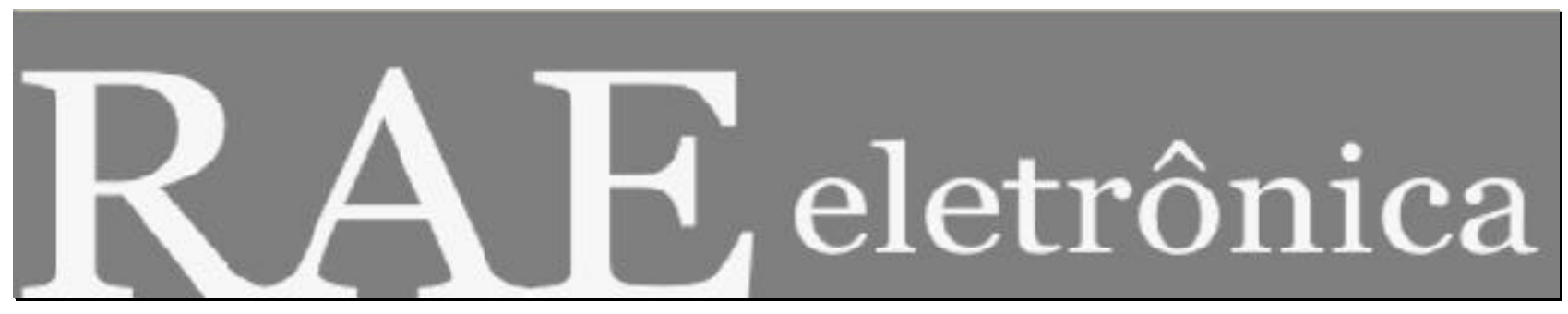

ARTIGOS

ARTÍCULOS

ARTICLES

CARACTERÍSTICAS DO NEGÓCIO NO SETOR DE MÁQUINAS AGRÍCOLAS

CARACTERÍSTICAS DEL NEGÓCIO EN EL SECTOR DE MÁQUINAS AGRÍCOLAS

BUSINESS CHARACTERISTICS IN THE FARMING IMPLEMENTS BUSINESS

Por:

CÁSSIA APARECIDA PASQUAL, UFRGS

EUGENIO ÁVILA PEDROZO, UFRGS

RAE-eletrônica, v. 6 n. 1 Art. 3, jan./jun. 2007

http://www.rae.com.br/eletronica/index.cfm?FuseAction=Artigo \&ID=4083\&Secao=ARTIGOS \&Volu $\mathrm{me}=6 \&$ Numero $=1 \&$ Ano $=2007$

(C) Copyright, 2007, RAE-eletrônica. Todos os direitos, inclusive de tradução, são reservados. É permitido citar parte de artigos sem autorização prévia desde que seja identificada a fonte. A reprodução total de artigos é proibida. Os artigos só devem ser usados para uso pessoal e nãocomercial. Em caso de dúvidas, consulte a redação: raeredacao@fgvsp.br.

A RAE-eletrônica é a revista on-line da FGV-EAESP, totalmente aberta e criada com o objetivo de agilizar a veiculação de trabalhos inéditos. Lançada em janeiro de 2002, com perfil acadêmico, é dedicada a professores, pesquisadores e estudantes. Para mais informações consulte o site www.rae.com.br/eletronica.

RAE-eletrônica

ISSN 1676-5648

(C)2007 Fundação Getulio Vargas - Escola de Administração de Empresas de São Paulo.

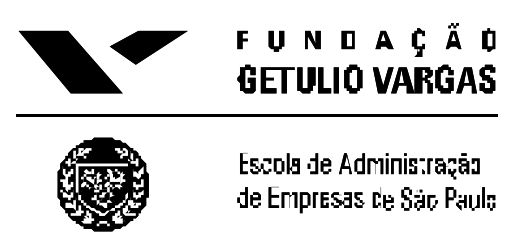




\section{ARTIGOS - CARACTERÍSTICAS DO NEGÓCIO NO SETOR DE MÁQUINAS AGRÍCOLAS}

Cássia Aparecida Pasqual - Eugenio Ávila Pedrozo

\section{RESUMO}

O presente artigo tem por objetivo avaliar as características do produto, da operação e da demanda no setor de máquinas e implementos agrícolas na mesorregião noroeste rio-grandense, procurando identificar padrões diferenciados do negócio em relação ao tamanho das empresas e às categorias de produtos, sob o enfoque do posicionamento logístico. Para isso, a partir de modelo de avaliação transversal, foi realizada uma pesquisa de campo de caráter exploratório e descritivo, considerando duas categorias de produtos, nos diferentes portes das empresas, numa amostra quase-aleatória com repetição. $\mathrm{Na}$ análise das características do negócio, de acordo com o porte das empresas e categoria dos produtos, as empresas apresentaram padrões heterogêneos de decisões logísticas, o que sugere, para o setor, a identificação dessas características para o melhor direcionamento da tomada de decisões pelos gestores.

\section{PALAVRAS-CHAVE}

Posicionamento logístico, concentração espacial, máquinas e implementos agrícolas, avaliação transversal, tomada de decisões logísticas.

\section{ABSTRACT}

The present article has the objective to rescue the origins of the space concentration of machines and implements industry in the Riograndense Northwest mesorregião, as well as, to evaluate the characteristics of the product, the operation and the demand. A comparative analysis was undertaken using different sizes of companies, identifying differentiated standards of the business in relation to the size of the companies and the categories of products, under the approach of the logistic positioning. For this, from the model of transversal evaluation, a research of field of exploratory and descriptive character was carried out, considering two categories of products, in the different sizes of the companies, in an almost-random sample with repetition. In the analysis of the business characteristics, in accordance with the sizes of the companies and categories of products, the companies had presented heterogeneous standards of logistic decisions suggesting that for the industry, the identification of these characteristics could lead to better decisions.

\section{KEYWORDS}

Logistic positioning, space localization, machines and agricultural implements, transversal evaluation, logistic decision making. 


\section{ARTIGOS - CARACTERÍSTICAS DO NEGÓCIO NO SETOR DE MÁQUINAS AGRÍCOLAS}

Cássia Aparecida Pasqual - Eugenio Ávila Pedrozo

\section{INTRODUÇÃO}

O agronegócio no Rio Grande do Sul corresponde a 36,84\% do PIB estadual, 47,45\% dos empregos e $69 \%$ das exportações estaduais, deixando em evidência sua importância relativa como alicerce para o desenvolvimento econô mico gaúcho (Finamore e Montoya, 2002). A competitividade no agronegócio tem sido objeto de diversos estudos e análises ao longo dos últimos anos. Um dos fatores principais deve-se ao fato de que as organizações começaram a perceber a necessidade de integr ar seus processos internos para garantir melhor nível de serviço e qualidade ao cliente, podendo assim se manter competitivas perante uma demanda cada vez mais exigente.

Dentre os setores que englobam o conjunto de fornecedores de insumos e bens de capital para os produtores rurais da economia gaúcha e brasileira, a montante dessa cadeia do agronegócio, e que vem se mostrando altamente perceptivo a essas mudanças competitivas, principalmente voltadas aos setores de produção e logística, é o setor de máquinas e implementos agrícolas. Convém mencionar que este se destacou no Brasil a partir da Segunda Guerra Mundial, com crescimento surpreendente até meados da década de 1970. Desse período até a metade da década de 1980, o setor entrou numa forte crise, declinando drasticamente e levando à falência muitas empresas nacionais. Na década de 1990, em virtude da política econômica implantada pelo governo Collor, este foi um dos segmentos industriais mais afetados. A adoção de juros de mercado para o financiamento da produção agrícola e as frustrações ocorridas nesta década, causadas, sobretudo, pela forte concorrência externa, somada a problemas estruturais como o difícil escoamento da produção, levou o setor de máquinas e implementos agrícolas a uma situação bastante desfavorável. Porém, aos poucos, no setor, a partir do final da década de 1990 e com mais intensidade na década atual, em razão das boas safras e melhores preços dos principais produtos agrícolas, a produção aumentou e a competitividade reapareceu.

Em conseqüência, nos últimos anos, as discussões sobre os processos de produção, de logística e as vantagens competitivas que conferem às empresas têm se tornado cada vez mais importantes no setor, entre eles o posicionamento logístico, que é o processo de integração de produção e logística que busca minimizar os custos para um determinado nível de serviço. No entanto, dentro deste contexto de posicionamento logístico, há uma questão de suma importância e ainda pouco discutida no setor de máquinas e implementos agrícolas. Considerando-se os novos padrões de competitividade que o processo de abertura econômica impõe às empresas de pequeno, médio e grande porte do setor, indaga- 


\section{ARTIGOS - CARACTERÍSTICAS DO NEGÓCIO NO SETOR DE MÁQUINAS AGRÍCOLAS \\ Cássia Aparecida Pasqual - Eugenio Ávila Pedrozo}

se: de que maneira as diferentes características do produto, da demanda e da operação constituem-se no meio ambiente determinante dos padrões de decisões logísticas?

Nesse sentido, no presente trabalho procura-se, na mesorregião noroeste do estado do Rio Grande do Sul, avaliar as características do negócio segundo uma análise comparativa entre os diferentes portes das empresas do setor, identificando padrões diferenciados do negócio em relação ao tamanho das empresas e às categorias de produtos.

Tratar desse tema é relevante na medida em que as informações geradas permitirão aos gestores do setor melhorar a tomada de decisão sobre posicionamento logístico em relação às características do negócio, que impactam de forma direta os diferentes tamanhos das empresas. Cabe destacar que a pesquisa foi realizada no setor de máquinas e implementos agrícolas, mais especificamente na mesorregião noroeste, no estado do Rio Grande do Sul, por ser uma das maiores regiões produtoras do setor e um importante fornecedor de bens de capital para o agronegócio gaúcho e brasileiro.

A seguir, o artigo abordará brevemente a análise transversal e longitudinal da estratégia logística e apresentará o processo metodológico aplicado. Posteriormente, se fará a identificação inicial das origens da localização espacial e das características do negócio das empresas do setor de máquinas e implementos agrícolas da mesorregião noroeste rio-grandense e se apresentarão as características do produto, da operação e da demanda segundo o tamanho das organizações estudadas. Finalmente se apresentam as principais conclusões desse trabalho.

\section{ENFOQUE TRANSVERSAL E LONGITUDINAL DA ESTRATÉGIA LOGÍSTICA PARA PRODUTOS ACABADOS}

Porter (1991) considera que para definir padrões de decisão e depois manter posições competitivas sustentáveis ao longo do tempo é necessário avaliar a estratégia empresarial a partir de dois níveis distintos e complementares, denominados transversal e longitudinal. O nível transversal trata da ligação entre as características internas e externas à empresa (produto, operação, mercado etc.) e o seu desempenho (lucratividade e retorno) num determinado período do tempo. Essa ligação ajuda a responder por que algumas empresas e posições dentro da própria indústria são mais atraentes que outras, ou, ainda, dentro de um conjunto de características, qual poderá ser o padrão de decisão mais apropriado. 


\section{ARTIGOS - CARACTERÍSTICAS DO NEGÓCIO NO SETOR DE MÁQUINAS AGRÍCOLAS}

Cássia Aparecida Pasqual - Eugenio Ávila Pedrozo

O nível longitudinal demonstra como determinadas empresas conseguiram (ou não) desenvolver posições de vantagem competitiva e sustentá-las (ou não) ao longo do tempo. O autor reforça que a análise do nível transversal é prioritária, uma vez que, sem uma compreensão específica sobre o que sustenta uma posição desejável, seria extremamente complexo lidar de forma analítica com o nível longitudinal.

Com relação à análise transversal da logística integrada como meio para criação de posições competitivas, Wanke (2003a, 2003b) menciona que a literatura focada em operações e serviços registra, de forma dispersa e difusa, que determinados padrões decisórios seriam mais apropriados e/ou seriam verificados com maior freqüência para um determinado conjunto de características do produto, da operação e da demanda. Para essas características, criaram-se indicadores que permitem a comparação, de forma mais consistente, para estudos dentro desses parâmetros. Christopher (2002) e Wanke (2003a) consideram que as características do produto englobariam o custo do produto vendido, a densidade de valor, o grau de obsolescência e o grau de perecibilidade. Características relevantes da operação logística envolveriam o valor do frete, tempo de resposta e grau de complexidade no fornecimento. Finalmente, as características da demanda envolveriam a amplitude de vendas, o giro dos estoques e a visibilidade da demanda.

\section{PROCEDIMENTOS METODOLÓGICOS}

\section{Modelo de avaliação transversal: indicadores das características do negócio}

Utilizando o enfoque da análise transversal de Porter (1991), a idéia básica do procedimento metodológico consiste na seguinte hipótese: As diferentes características do produto, da operação e da demanda constituem o meio ambiente determinante dos padrões de decisões logísticas, podendo ser diferenciados em relação ao tamanho das empresas e às categorias de produtos.

A fim de identificar essas características do negócio, a seguir são descritos os indicadores gerados com base nas informações coletadas na pesquisa de campo, sintetizadas na Figura 1.

Cabe salientar, entretanto, que esses indicadores foram utilizados por Christopher (2000 e 2002) e por Wanke (2003a), conforme já exposto, diferindo, no presente trabalho, nas características da operação e nas características da demanda, visto que se utilizou a razão entre prazos, ao invés de valor do frete nas características da operação, e agregou-se prazo de entrega e concorrentes diretos nas características da demanda. Essas diferenças foram incluídas pelo Centro de Estudos em Logística da 


\section{ARTIGOS - CARACTERÍSTICAS DO NEGÓCIO NO SETOR DE MÁQUINAS AGRÍCOLAS \\ Cássia Aparecida Pasqual - Eugenio Ávila Pedrozo}

Coppead/RJ, em função da adequação do instrumental de coleta de dados com a existência de informações confiáveis nas empresas.

A definição das variáveis das características do negócio é apresentada no Quadro 1.

\section{Figura 1 - Indicadores das características do produto, da operação e da demanda}

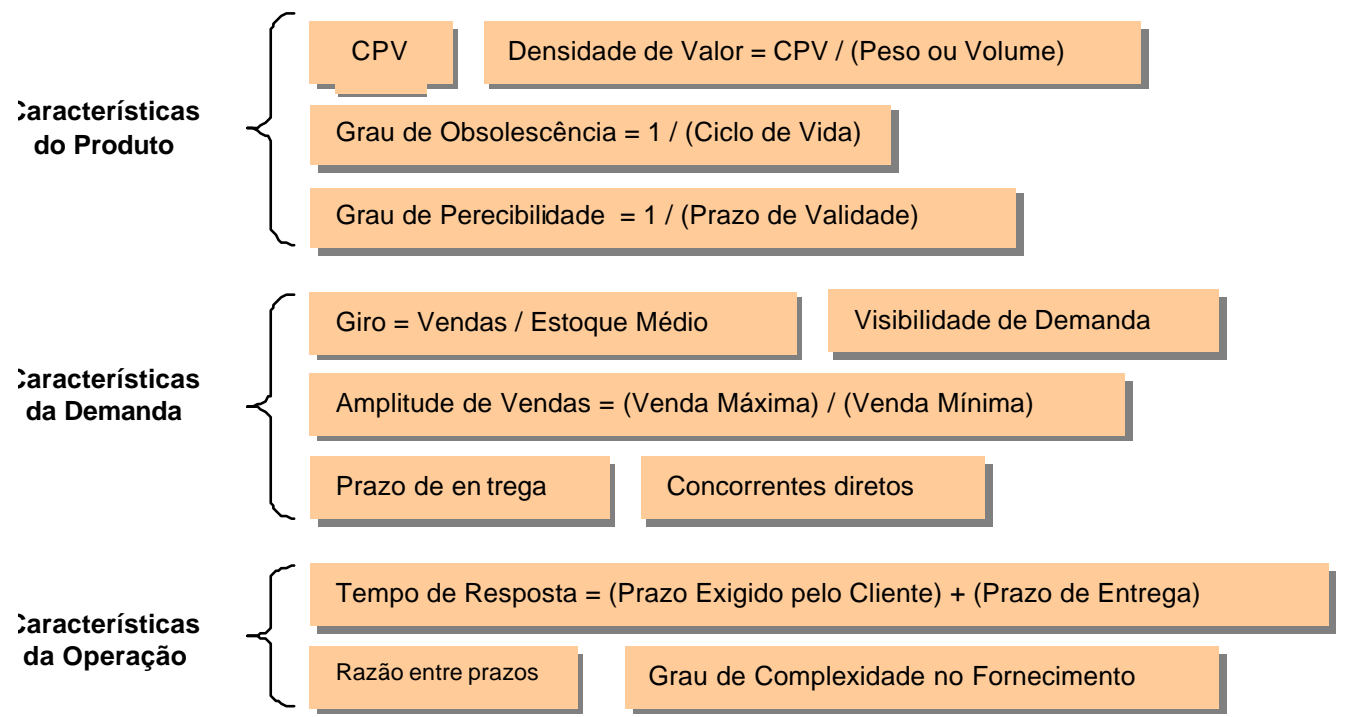

Fonte: Elaborado com base em Christopher (2000 e 2002) e Wanke (2003a).

Quadro 1 - Operacionalização e descrição das variáveis coletadas na pesquisa de campo

\begin{tabular}{|c|c|}
\hline CARACTERÍSTICAS DO NEGÓCIO & DEFINIÇĀO \\
\hline \multicolumn{2}{|l|}{ CARACTERÍSTICAS DO PRODUTO } \\
\hline Custo do Produto Vendido - CPV & $\begin{array}{l}\text { É o volume de capital de giro necessário para produzir uma } \\
\text { unidade adicional. }\end{array}$ \\
\hline Densidade de Valor - DV & E a divisão do CPV pelo peso do produto \\
\hline Grau de Obsolescência - GO & E o inverso do tempo do ciclo de vida do produto \\
\hline Grau de Perecibilidade - GP & E o inverso do prazo de validade dos produtos \\
\hline \multicolumn{2}{|l|}{ CARACTERÍSTICAS DA DEMANDA } \\
\hline Giro de estoque $-\mathrm{GE}$ & $\begin{array}{l}\text { É a divisão do número de dias do ano pelo número de dias de } \\
\text { venda em estoque do produto. }\end{array}$ \\
\hline Amplitude de Vendas - AV & $\begin{array}{l}\text { E a divisão da venda mensal máxima pela venda mensal mínima } \\
\text { de um produto. }\end{array}$ \\
\hline Visibilidade da demanda - VD & 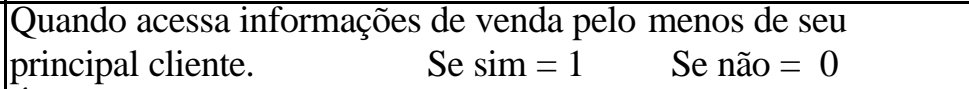 \\
\hline Concorrentes Diretos - CD & E o número total de concorrentes \\
\hline Prazo de Entrega - PE & $\begin{array}{l}\text { E o prazo desde a colocação do pedido pelo cliente até sua } \\
\text { entrega }\end{array}$ \\
\hline \multicolumn{2}{|l|}{ CARACTERÍSTICAS DA OPERAÇÃO } \\
\hline & $\begin{array}{l}\text { natório do tempo de recebimento do insumo mais } \\
\text { do com o tempo de entrega do produto para o principal }\end{array}$ \\
\hline
\end{tabular}


ARTIGOS - CARACTERÍSTICAS DO NEGÓCIO NO SETOR DE MÁQUINAS AGRÍCOLAS

Cássia Aparecida Pasqual - Eugenio Ávila Pedrozo

\begin{tabular}{|l|l|}
\hline Tempo de resposta - TR & cliente \\
\hline $\begin{array}{l}\text { Grau de Complexidade no Fornecimento- } \\
\text { GCF }\end{array}$ & $\begin{array}{l}\text { E a multiplicação do número de fornecedores pelo número de } \\
\text { itens de matéria -prima. }\end{array}$ \\
\hline Razão entre prazos - RP & $\begin{array}{l}\text { E o coeficiente entre o prazo de entrega do produto acabado para } \\
\text { o cliente e o prazo de entrega da matéria -prima pelo fornecedor }\end{array}$ \\
\hline
\end{tabular}

Fonte: Elaborado com base em Wanke (2003a) e Pagh e Cooper (1998).

\section{Área de abrangência da pesquisa e tamanho da amostra}

A mesorregião noroeste do estado do Rio Grande do Sul (veja Figura 2) é formada por 13 unidades territoriais ou microrregiões, segundo o Instituto Brasileiro de Geografia e Estatística - IBGE (2004), compreendendo um total de 216 municípios, o que perfaz 43,55\% dos municípios do Rio Grande do Sul. A região caracteriza-se por apresentar uma produção agropecuária significativa do estado, em particular, nas atividades de produção de grãos, de leite, de aves e de culturas forrageiras.

Figura 2 - Unidades territoriais do nível mesorregião geográfica do estado do Rio Grande do Sul

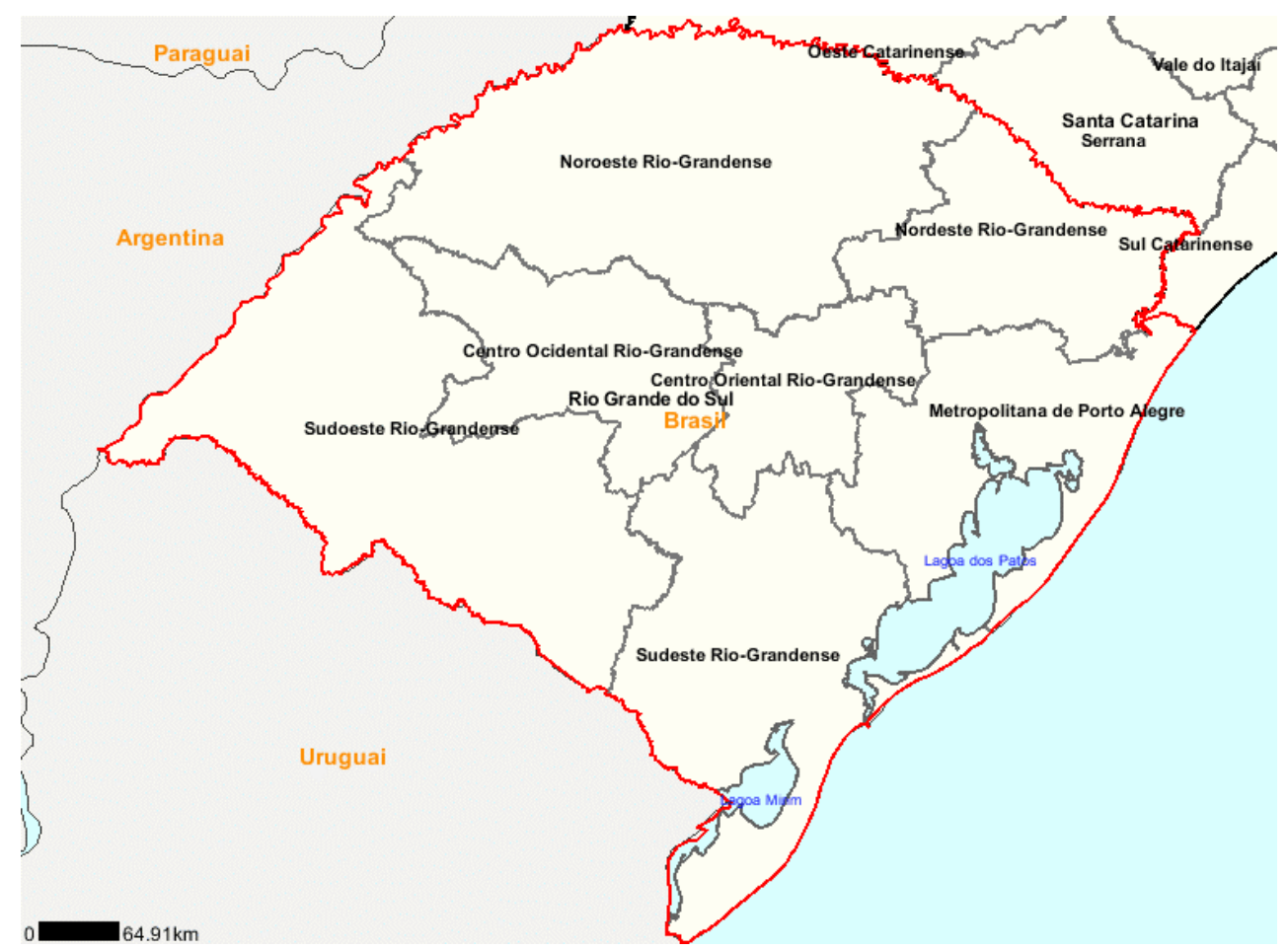

Fonte: IBGE (2004).

Conforme o cadastro do Sindicato de Máquinas do Estado do Rio Grande do Sul - Simers (2004), o estado do Rio Grande do Sul detém $62 \%$ da produção do setor de máquinas e implementos 


\section{ARTIGOS - CARACTERÍSTICAS DO NEGÓCIO NO SETOR DE MÁQUINAS AGRÍCOLAS \\ Cássia Aparecida Pasqual - Eugenio Ávila Pedrozo}

agrícolas nacional. $\mathrm{O}$ estado gaúcho apresenta um total de 45 empresas (fábricas) no setor, das quais 35 estão localizadas na mesorregião noroeste, o que confere à mesorregião uma participação de 77,78\% do estado e $48 \%$ da indústria nacional. Não foram incluídas na análise as empresas fornecedoras, fabricantes de peças e acessórios. Dessa forma, reduziu-se a amostra para 28 empresas na região. Ainda, pelo fato de algumas empresas inicialmente contatadas, no momento da aplicação do questionário, terem se recusado a participar da pesquisa de campo, por considerarem que as informações solicitadas eram de caráter sigiloso, chegouse a uma amostra final de 21 empresas, perfazendo $75 \%$ do total da região.

Em virtude desses fatores, deve-se destacar que a pesquisa foi realizada a partir de uma amostra obedecendo a um processo quase-aleatório com repetição. A Tabela 1 mostra os tamanhos amostrais e as frações coletadas na região. Para a classificação do tamanho das empresas utilizaram-se critérios do Finame para o BNDES (2003), em que se consideram pequenas as empresas cuja receita operacional bruta anual ou anualizada for inferior ou igual a R 7.875 mil; médias, quando superar R $\$ 7.875$ mil e for inferior ou igual a R \$ 45 milhões; grandes, quando a receita operacional bruta anual ou anualizada superar R\$ 45 milhões.

Tabela 1 - Universo, amostra e frações amostrais coletadas na pesquisa de campo

\begin{tabular}{lrcrc}
\hline \multicolumn{1}{c}{$\begin{array}{c}\text { Porte das } \\
\text { Empresas }\end{array}$} & Universo $\begin{array}{c}\text { Universo Considerado } \\
\text { na Pesquisa }\end{array}$ & Amostra & $\begin{array}{c}\text { Fração } \\
\text { Amostral Final }\end{array}$ \\
\hline Pequenas & 16 & 12 & 10 & $83,33 \%$ \\
Médias & 11 & 9 & 6 & $66,67 \%$ \\
Grandes & 8 & 7 & 5 & $71,43 \%$ \\
Total na Mesorregião & 35 & 28 & 21 & $75,00 \%$ \\
\hline Total do RS & 45 & 45 & 21 & $46,67 \%$ \\
\hline
\end{tabular}

Tendo em vista que as decisões logísticas das empresas podem variar para cada produto comercializado em função da importância relativa do faturamento para a empresa, com o fim de se evitar esse problema, bem como de avaliar padrões de decisão, estabeleceramse para a análise duas categorias de produto (Stock Keeping Unit - SKU), ou seja, solicitou-se que cada empresa respondesse ao mesmo conjunto de perguntas avaliando dois produtos distintos (SKUs diferentes). O primeiro conjunto de respostas referiu-se a um SKU de grande representatividade para o faturamento da empresa, denominado SKU classe A; o segundo grupo de respostas avaliou um SKU de baixa representatividade em faturamento, denominado $S K U$ classe $C$. 


\section{Características do questionário da pesquisa de campo}

O questionário utilizado foi elaborado por pesquisadores do Centro de Estudos em Logística da Coppead/RJ (COPPEAD, 2004) e seus itens permitem caracterizar as decisões logísticas de cada empresa, assim como as características do negócio em que atuam. O instrumento é composto por questões factuais, que assim foram definidas por simplificarem o projeto do questionário, pois foram formuladas diferentes alternativas para uma mesma pergunta. Outra vantagem é a possibilidade de o entrevistador interagir com o entrevistado de modo a assegurar o correto entendimento das perguntas. Em todas as 21 empresas componentes da amostra obteve-se a participação de duas pessoas entre gerentes e supervisores responsáveis pela área de produção e logística, que responderam ao questionário.

\section{ANÁLISE DAS ORIGENS DA LOCALIZAÇÃO ESPACIAL E DAS CARACTERÍSTICAS DO NEGÓCIO}

Com base na pesquisa de campo, pôde-se chegar aos dois objetivos propostos no trabalho: os fatores que contribuíram para a localização espaciale as características gerais do negócio no setor de máquinas e implementos agrícolas e a identificação dos determinantes dos padrões de decisões, nos diferentes tamanhos das empresas, baseado na análise das características do produto, da operação e da demanda.

\section{Origens da concentração espacial}

Desde a era colonial a agricultura tem sido a principal responsável pelo crescimento da economia brasileira. Nesse contexto, a imigração européia para o Brasil no final do século XIX foi um fato importante para esse crescimento. Entretanto, na década de 1960, a maior parte de máquinas e implementos agrícolas eram importados, em particular, as peças de reposição.

Atualmente, o setor de máquinas e implementos agrícolas é competitivo em âmbito nacional e internacional, com um crescimento de 24\% em 2003 (BACEN, 2003). Chama-se a atenção que, segundo o SIMERS (2004), no Brasil pouco mais de $60 \%$ das empresas do setor estudado localizam-se no estado do Rio Grande do Sul, e, desse total, em torno de $78 \%$ estão na mesorregião noroeste riograndense. Pelos depoimentos colhidos na pesquisa de campo, relatou-se que o processo de imigração européia para o Brasil, em particular nas décadas de 1930 e 1940, provenientes da Holanda, Alemanha e Itália explica em parte essa localização espacial das indústrias desse setor na mesorregião noroeste. 


\section{ARTIGOS - CARACTERÍSTICAS DO NEGÓCIO NO SETOR DE MÁQUINAS AGRÍCOLAS}

Cássia Aparecida Pasqual - Eugenio Ávila Pedrozo

Seu surgimento deveu-se a esses imigrantes que vieram ao Brasil para trabalhar na agricultura, mas que detinham conhecimentos de metalurgia e mecânica. Naquela época as máquinas e implementos agrícolas no Brasil eram importados em sua quase totalidade, incluindo peças de reposição. Não havia nem mesmo oficinas de manutenção ou reparo. Muitos desses agricultores imigrantes, percebendo a falta e a grande necessidade, passaram a fabricar artesanalmente essas peças, bem como algumas máquinas e implementos agrícolas. Cabe destacar que essa nova atividade teve início nos municípios de Panambi, Não-Me-Toque, Carazinho, Horizontina e Passo Fundo. Com o tempo, o setor foi se consolidando e fortalecendo.

Inicialmente muitas dessas empresas tiveram características familiares na administração e na produção de produtos, e muitas destas ainda existem. Contudo, verificou-se que o número de empresas no setor está aumentando rapidamente em virtude de sua divisão por razões familiares e patrimoniais. Observou-se também o surgimento de uma segunda geração de empresas de fundo de quintal, além de outras já consolidadas de portes pequeno, médio e grande. Os donos dessas empresas são dissidentes familiares que participavam de empresas tradicionais; freqüentemente, são ex-funcionários que aprenderam as técnicas de produção. Em muitos casos são empregados demitidos em razão do processo de automação de muitas empresas de médio e grande porte do setor.

Cabe salientar que algumas empresas do ramo com sede na Europa, visualizando o mercado potencial brasileiro e a disponibilidade de mão-de-obra qualificada na região, instalaram-se na mesorregião noroeste do estado, o que também impulsionou, difundiu e acelerou o processo de inovação tecnológica no setor. Verificoutse também que o nível de concorrência no setor é tão acirrado, a ponto de gerar problemas judiciais sobre patentes em empresas vizinhas. $\mathrm{O}$ setor, atualmente, tem uma capacidade instalada que lhe permite exportar produtos para diferentes países do mundo, inclusive para países europeus e para os Estados Unidos.

Portanto trata-se de um setor altamente competitivo, com uma dinâmica permanente de inovação tecnológica caracterizada pelo permanente lançamento de novos modelos de máquinas e implementos agrícolas que reduzem custos e aumentam a produtividade nas atividades locais. Muitas tecnologias hoje utilizadas pelas empresas agrícolas podem ser consideradas, em muitos casos, 100\% nacionais, por terem sido criadas e patenteadas no país.

\section{Caracterização do porte das empresas}




\section{ARTIGOS - CARACTERÍSTICAS DO NEGÓCIO NO SETOR DE MÁQUINAS AGRÍCOLAS \\ Cássia Aparecida Pasqual - Eugenio Ávila Pedrozo}

As variáveis que podem diferenciar o porte das empresas em grandes, médias e pequenas, segundo a pesquisa de campo, podem ser estabelecidas com base no faturamento, número de funcionários e de produtos acabados.

Dessa forma, as características gerais do negócio no setor de máquinas e implementos agrícolas indicam, em termos médios, que o faturamento em reais anual das empresas grandes é de 173 milhões; das empresas médias, de 19 milhões; e das pequenas empresas, em torno de 3 milhões. Essas diferenças marcantes são observadas também pelo número de funcionários, bem como pelos produtos acabados (veja a Tabela 2).

Tabela 2: Características gerais do negócio no setor de máquinas e implementos agrícolas médias por portes das empresas

\begin{tabular}{llrrrrrr}
\hline $\begin{array}{l}\text { Porte das } \\
\text { empresas }\end{array}$ & $\begin{array}{l}\mathrm{N}^{\mathrm{o}} \text { de } \\
\text { empresas } \\
\text { entrevistadas }\end{array}$ & \multicolumn{1}{l}{$\begin{array}{l}\text { Faturamento } \\
\mathrm{R} \$\end{array}$} & \multicolumn{2}{l}{$\begin{array}{l}\mathrm{N}^{\mathrm{o}} \text {. de } \\
\text { funcionários } \mathrm{N}^{\mathbf{0}} \text {. de clientes fornecedores }\end{array}$} & $\begin{array}{l}\mathrm{N}^{\mathrm{o}} \text {. de itens } \\
\text { de matéria- } \\
\text { prima }\end{array}$ & $\begin{array}{l}\text { Produtos } \\
\text { acabados }\end{array}$ \\
\hline Grande & 05 & 173.385 .407 & 1.177 & 7.574 & 4.740 & 80.273 & 5.862 \\
Média & 06 & 19.299 .793 & 155 & 1.372 & 126 & 289 & 343 \\
Pequena & 10 & 2.884 .700 & 51 & 1.447 & 122 & 319 & 54 \\
\hline Media Geral & 07 & 48.170 .133 & 349 & 2.884 & 1.223 & 19.347 & 1.519
\end{tabular}

Com esses resultados percebe-se claramente a heterogeneidade empresarial existente no setor e que em muitos casos tem matizes de complementaridade (empresas prestando serviços para outras) e competitividade empresarial (em todos os portes empresariais dos setores). Isso significa que o nível de complementaridade e competitividade no setor de acordo com o porte empresarial tem direcionamentos diferentes. Por exemplo, empresas pequenas concorrendo com grandes empresas, grandes concorrendo com pequenas, médias prestando serviços para grandes ou para pequenas etc.

\section{Análise das características do negócio de acordo com o porte das empresas}

Considerando a hipótese de que as diferentes características do produto, da operação e da demanda constituem o meio ambiente determinante dos padrões de decisões logísticas, a seguir avaliam-se as características do negócio segundo uma análise comparativa entre os portes das empresas e as categorias dos produtos.

\section{Características do produto}




\section{ARTIGOS - CARACTERÍSTICAS DO NEGÓCIO NO SETOR DE MÁQUINAS AGRÍCOLAS \\ Cássia Aparecida Pasqual - Eugenio Ávila Pedrozo}

Conforme a Figura 3, o custo do produto vendido mostra que o SKU A, independentemente do porte, é significativamente maior que o SKU C, resultado esse esperado, uma vez que o SKU A, tanto para as empresas grandes como para as médias e pequenas, sempre foi um produto de alto valor e o SKU C, um produto de baixo valor. Para as empresas pequenas e grandes, a diferença do CPV dos produtos de menor valor com os de maior valor oscilou em torno de três vezes. Já para as médias empresas, a diferença foi altamente significativa ( $\mathrm{R} \$ 6.331,00$ e $\mathrm{R} \$ 41.216,00)$, chegando a quase sete vezes a diferença entre o SKU A e o SKU C. Esses resultados indicam um desvio-padrão elevado (R\$ $22.698,24)$, que mostra um nível heterogêneo de volume de capital de giro utilizado para a produção dos SKUs nos diferentes portes de e mpresas.

Figura 3 - Características do produto para o SKU A e SKU C de acordo com o porte das empresas

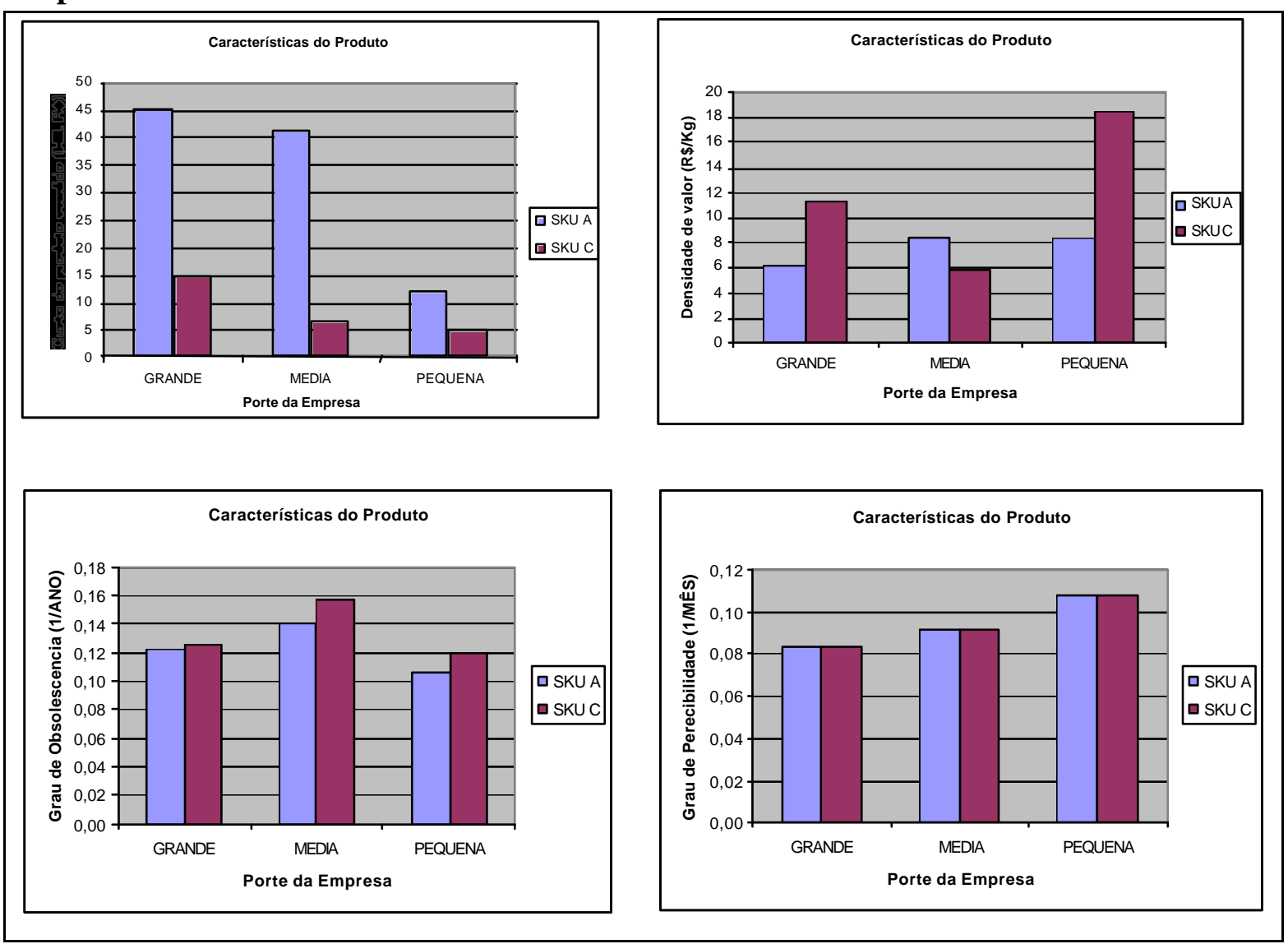

A densidade de valor permite uma comparação mais consistente entre produtos diferentes de um mesmo setor, bem como a comparação entre os diferentes portes de empresas. Pelos resultados, 


\section{ARTIGOS - CARACTERÍSTICAS DO NEGÓCIO NO SETOR DE MÁQUINAS AGRÍCOLAS}

Cássia Aparecida Pasqual - Eugenio Ávila Pedrozo

nota-se que, para o SKU de maior importância para as empresas do setor, tanto as de pequeno como as de médio porte apresentaram a mesma densidade de valor, sendo superior ao verificado na grande empresa. Já para o SKU C, a maior densidade de valor é apresentada nas pequenas empresas, custando aproximadamente $R \$ 18,00$ por quilograma do produto vendido, ou seja, três vezes mais que para as empresas de porte médio, que apresentaram a menor densidade ( $\mathrm{R}$ 6,00). Esse fato chama a atenção, pois era de se esperar que as empresas de pequeno porte apresentassem menor densidade de valor, em função do seu baixo faturamento. No entanto, a explicação para o fato está mais relacionada não com o faturamento, mas com a diferenciação do produto devido à inovação tecnológica.

O grau de obsolescência é um fator fundamental para a estruturação da cadeia logística. Com a tendência atual de encolhimento do tempo do ciclo de vida dos produtos, as empresas tendem a estruturar suas operações de forma a permitir um rápido escoamento da produção, ou mesmo, em alguns casos, a produzir um "contrapedido" do cliente. Nesse sentido, pela Figura 3, evidencia-se que o maior grau de obsolescência em relação ao porte das empresas apresentou-se nas de tamanho médio, tanto para o SKU A quanto para o SKU C. Duas observações podem ser feitas neste indicador. Primeiramente o grau de obsolescência de todo setor, para ambas as categorias, foi semelhante, e em segundo lugar o grau de obsolescência apresentourse muito baixo, o que já era de se esperar, pelo fato de ser mais longo o ciclo de vida dos produtos. Todavia, deve-se considerar que, dado o número expressivo de lançamentos de novos produtos no setor, a obsolescência está tendendo a aumentar devido à defasagem tecnológica, que aumenta os graus de obsolescência do produto.

Por fim, o grau de perecibilidade mostra que os dois SKUs apresentaram a mesma perecibilidade, mudando apenas conforme o porte, ou seja, conforme aumenta o porte das empresas, diminui o grau de perecibilidade. Esse fato mostra que as empresas de grande porte, que se caracterizam por produzir um grande número de produtos diferentes e em quantidades elevadas, exigem a utilização de maior capital de giro e níveis tecnológicos mais elevados, concedendo, então, tempos de garantia menores para seus produtos. No caso das empresas de médio e pequeno porte, pelo fato de produzirem um número pequeno de produtos e, portanto, terem uma necessidade menor de recursos financeiros, conferem um período maior de garantia, o que diminui o grau de perecibilidade.

\section{Características da demanda}

Conforme pode ser visto na Figura 4, o giro de estoque constitui um indicador que merece muita atenção quando se busca um bom gerenciamento de estoques da empresa. No setor analisado, para o SKU A, independentemente do tamanho, o número de giros por ano é semelhante, sendo de 


\section{ARTIGOS - CARACTERÍSTICAS DO NEGÓCIO NO SETOR DE MÁQUINAS AGRÍCOLAS \\ Cássia Aparecida Pasqual - Eugenio Ávila Pedrozo}

aproximadamente 30 vezes ao ano (2,5 vezes ao mês). Para o SKU C, o giro é bem menor, especialmente para pequenas empresas, que giram seus estoques apenas cinco vezes ao ano. No entanto, esse fato evidencia, em termos relativos, que no setor o giro de estoques é elevado, uma vez que a maior parte dos produtos fabricados pelas diferentes empresas é feita "contrapedido". Embora possa parecer baixo o nível de estoque, por tratar-se de produtos produzidos "contrapedido", os indicadores mostram o contrário, isto é, apresentam estoques elevados.

Figura 4 - Características da demanda para o SKU A e o SKU C de acordo com o porte das empresas

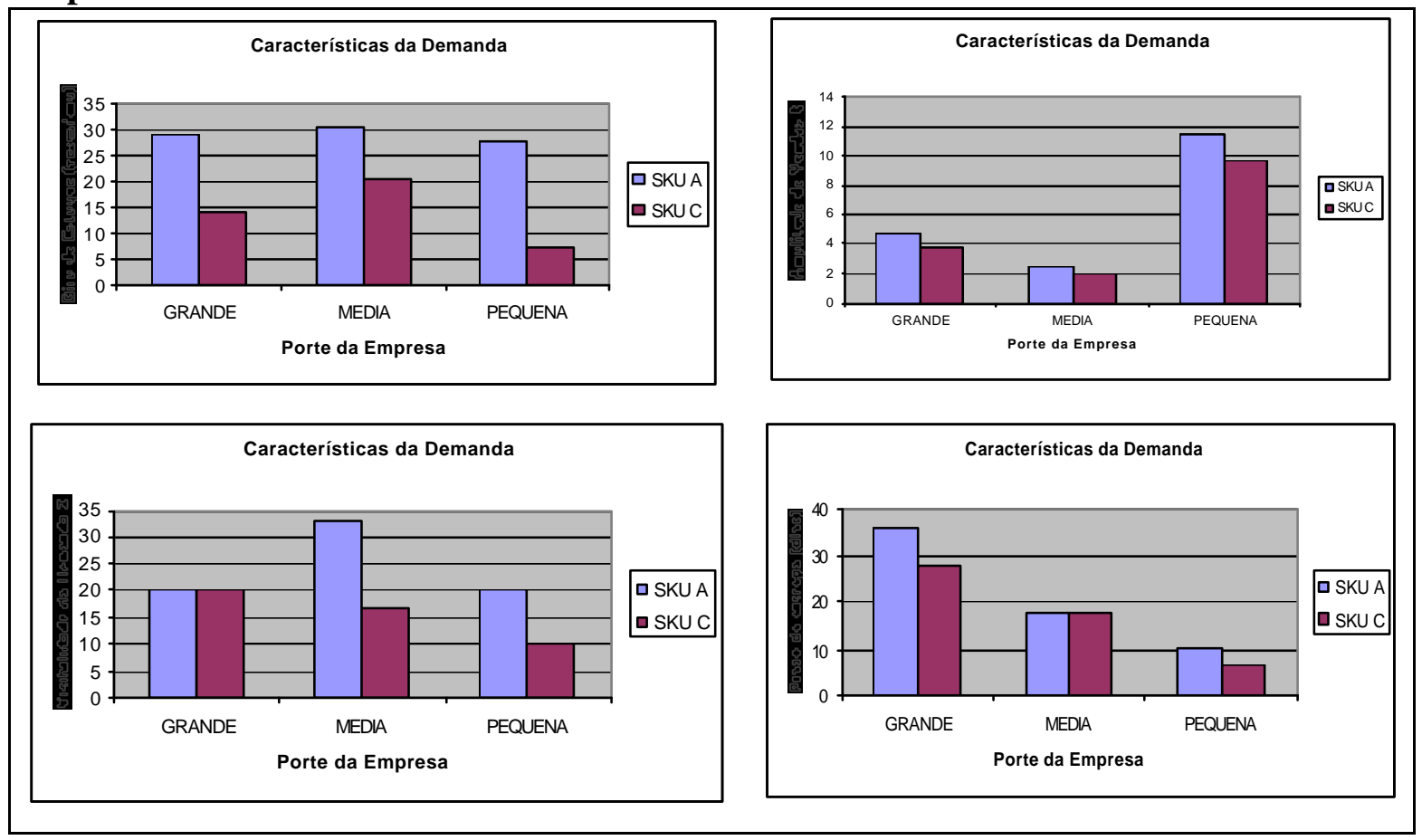




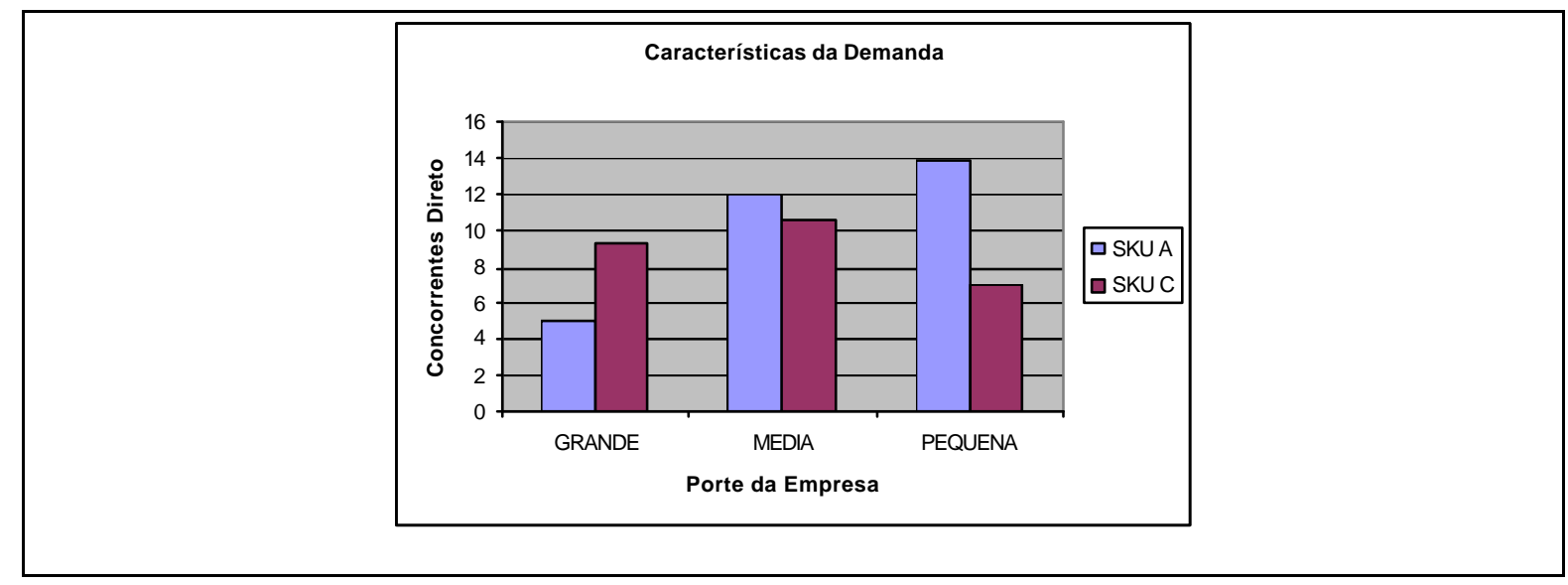

A amplitude de vendas permite analisar a sazonalidade dos produtos. A Figura 4 evidencia que as empresas pequenas, para ambos os SKUs, apresentam uma elevada amplitude nas vendas, caracterizando uma elevada tendência sazonal. Por sua vez para as empresas de porte médio e grande, a amplitude de vendas mostra que, mesmo estando sujeitas à sazonalidade, elas conseguem reduzir a amplitude de vendas, o que sugere melhor planejamento na produção, que em muitos casos é programada em função de acionamento de produção "contrapedido".

Uma empresa pode visibilizar a demanda se acessar informações sobre as vendas do consumidor final em tempo real (Christopher, 2000) ou, pelo menos, do cliente principal (Wanke, 2001). Todavia a pesquisa de campo revelou que para o setor analisado a reação das empresas não se baseia na visibilidade da demanda, já que apenas as empresas médias apresentaram uma relativa significância neste indicador (34\%) no SKU A. Para as grandes empresas, tanto usando o SKU A como o SKU C, as informações de venda baseadas na demanda real apresentaram se como pouco significativas (20\%) para as empresas.

No indicador prazo de entrega, as empresas de porte médio apresentaram o mesmo prazo para ambos os SKUs (18 dias). As grandes empresas demoram a entregar seus produtos acabados, desde a colocação do pedido pelo cliente, em torno de 36 dias para o SKU A e de 28 dias para o SKU C. Por sua vez, as pequenas empresas apresentaram o menor tempo de entrega de todo o setor: 10 dias para o SKU A e 7 dias para o SKU C. Essas informações evidenciam o nível de agilidade mais elevado nas empresas de pequeno porte no setor, em particular, por apresentarem um número de itens de produtos acabados menor e projetos de produtos e processos produtivos mais simplificados. Outro fator que explica essa rapidez no recebimento do produto pelo cliente está relacionado à amplitude de vendas, pois, como essas empresas apresentam uma grande amplitude de vendas, esse período sazonal é aproveitado para a fabricação e montagem de peças. 


\section{ARTIGOS - CARACTERÍSTICAS DO NEGÓCIO NO SETOR DE MÁQUINAS AGRÍCOLAS \\ Cássia Aparecida Pasqual - Eugenio Ávila Pedrozo}

Por fim, o número de concorrentes diretos que uma empresa pode ter é um fator de grande representatividade no momento da tomada de decisão. A Figura 4 mostra que para as grandes empresas seus produtos de maior faturamento apresentam um menor número de concorrentes diretos, o que leva a perceber que esses são produtos diferenciados, sem muitos similares no mercado. O contrário acontece com as empresas de pequeno porte, cujos produtos de maior faturamento são os que mais têm concorrência em todo o setor. Quanto às empresas de porte médio, sofrem concorrência em ambos os produtos. Num contexto geral, a concorrência, com exceção do SKU A das grandes empresas, é bastante acirrada no setor, apesar da grande diversificação de modelos de náquinas e implementos agrícolas que são lançados periodicamente por todas as empresas, numa permanente inovação tecnológica.

\section{Características da operação}

$\mathrm{O}$ indicador tempo de resposta permite que se verifique o tempo decorrido entre o recebimento do insumo que mais tempo leva a chegar e a entrega do produto final ao cliente. A Figura 5 mostra que as grandes empresas apresentam um tempo de resposta bastante elevado, que se deve, conforme verificado nas entrevistas, ao fato de demandarem matérias-primas importadas de recebimento mais tardio. Nas empresas de porte médio, o mesmo acontece com o SKU A. No entanto, para o SKU C houve o menor tempo de resposta do setor, demonstrando maior agilidade em termos de suprimento e distribuição.

Figura 5 - Características da operação para o SKU A e SKU C de acordo com o porte das empresas

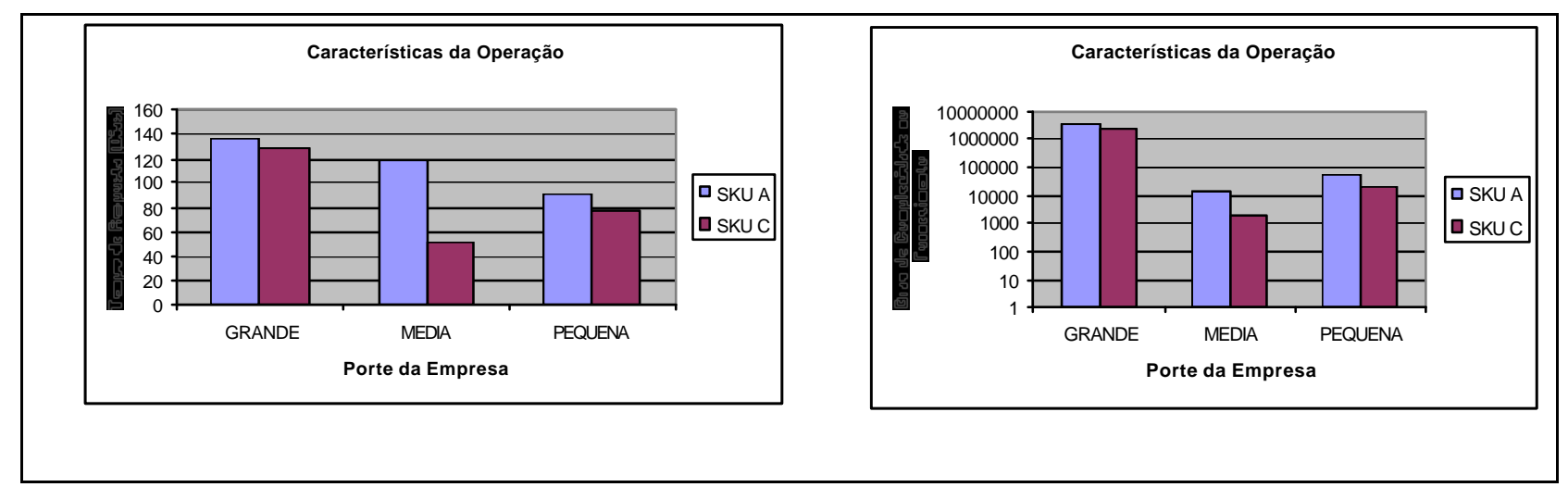




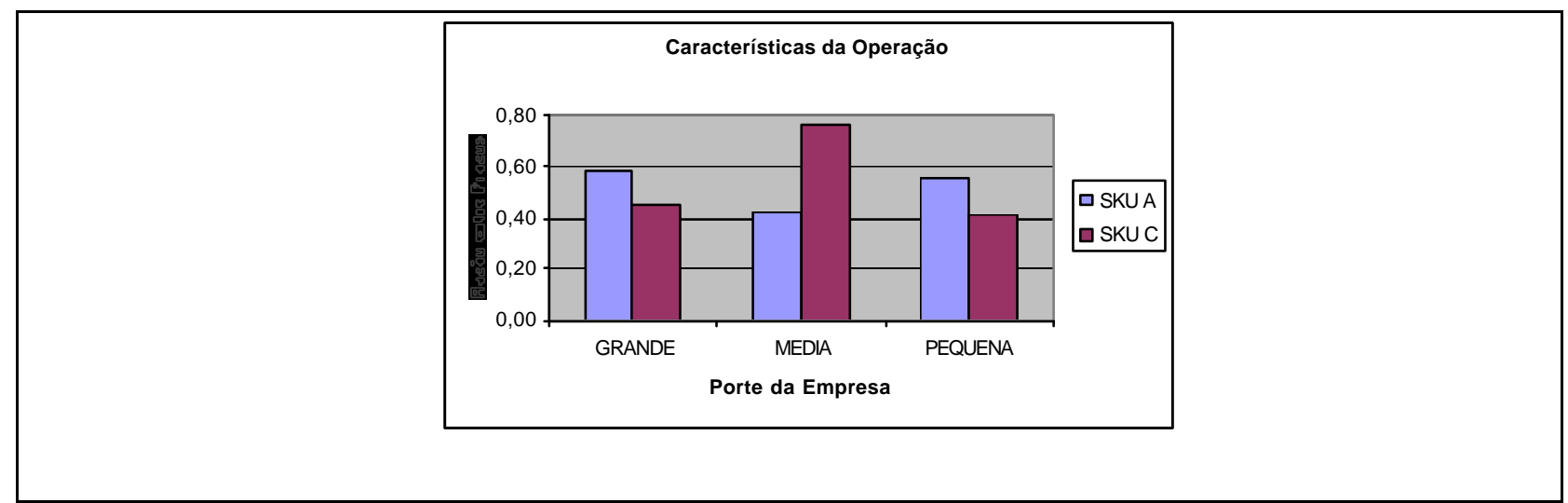

O grau de complexidade no fornecimento no setor analisado evidenciou que as grandes empresas têm um número muito elevado de itens de matérias-primas para a fabricação de seus produtos, principalmente para o SKU A, dado que são de dimensões maiores e de valores bastante altos. As empresas de porte médio e pequeno tiveram um baixo grau de complexidade no fornecimento, pois os seus itens de matérias-primas são em menor número, até porque apresentam um processo de produção mais simples, trabalhando mais com a montagem do que com a fabricação de peças. Já as grandes empresas fabricam um grande número de peças, abrangendo grande parte da cadeia produtiva e até mesmo a pintura do produto acabado, o que aumenta consideravelmente o número de itens de matéria-prima.

Por fim, a razão entre prazos foi maior nas empresas de porte médio com o SKU C, demonstrando que para essas a capacidade de resposta para o cliente é mais flexível e de menor custo. As grandes e pequenas empresas apresentaram uma razão entre prazos bastante similar.

Em síntese, o conjunto de características do produto, da demanda e da operação apresenta padrões heterogêneos na dependência do porte. Verifica-se no setor de máquinas e implementos agrícolas a coexistência de diferentes fatores que podem contribuir para a tomada de decisões logísticas e para a gestão dos estoques, independentemente de concorrerem entre si ou de atuarem de forma complementar.

\section{CONSIDERAÇÕES FINAIS}




\section{ARTIGOS - CARACTERÍSTICAS DO NEGÓCIO NO SETOR DE MÁQUINAS AGRÍCOLAS}

Cássia Aparecida Pasqual - Eugenio Ávila Pedrozo

Este trabalho teve como objetivo resgatar as origens da localização espacial, avaliar as características do negócio e fazer uma análise comparativa entre os diferentes portes das empresas da indústria de máquinas e implementos agrícolas na mesorregião noroeste do Rio Grande do Sul.

Verificou-se que as causas para a elevada concentração de localização de empresas do setor na mesorregião noroeste rio-grandense deveutse principalmente aos imigrantes europeus que vieram ao Brasil para trabalhar na agricultura. Mas seus conhecimentos de metalurgia e mecânica e a percepção da falta de máquinas e implementos agrícolas - além das peças de reposição - os levaram a empreender, criando empresas que se consolidaram. Como muitas dessas empresas tinham características familiares, as divisões por herança fizeram com que o número de empresas do setor aumentasse rapidamente.

Outro fator observado foi o surgimento de uma segunda geração de empresas de fundo de quintal. Havia outras já consolidadas de portes pequeno, médio e grande, propriedades de dissidentes familiares que participavam de empresas tradicionais e que aprenderam técnicas de produção, e especialmente ex-funcionários, demitidos em razão do processo de automação de muitas empresas de médio e grande porte do setor. Além disso, algumas empresas do ramo com sede na Europa, percebendo o mercado potencial brasileiro e a disponibilidade de mão-de-obra qualificada na região, instalaram-se na mesorregião noroeste do estado, o que também impulsionou, difundiu e acelerou o processo de inovação tecnológica no setor.

Considerando-se as diferentes características do produto, da operação e da demanda como constituintes do meio ambiente determinante dos padrões de decisões logísticas, verificourse que, dentre as características do produto, o custo do produto vendido mostrou um nível heterogêneo no volume de capital de giro necessário, independentemente do tamanho das empresas. A densidade de valor foi maior nas pequenas empresas do que nas médias e grandes, sugerindo que a produção está mais relacionada com a diferenciação de produtos via inovação tecnológica que com o faturamento. $\mathrm{O}$ grau de obsolescência foi maior nas médias empresas, no entanto apresentando-se baixo para todo o setor. Mas deve ser registrado que, dado o número expressivo de lançamentos de novos produtos no setor, a obsolescência tende a aumentar. Assim, em razão dessa tendência de encolhimento do tempo do ciclo de vida dos produtos, as empresas do setor estruturaram suas operações de forma a permitir um rápido escoamento da produção e, fundamentalmente, produzir "contrapedido" do cliente. O grau de perecibilidade indicou que à medida que aumenta o porte das empresas, diminui a perecibilidade de seus produtos. Portanto, as empresas de grande porte, que se caracterizam por produzir grande número de produtos diferentes e em quantidades elevadas, apresentam maior necessidade de capital de giro. 


\section{ARTIGOS - CARACTERÍSTICAS DO NEGÓCIO NO SETOR DE MÁQUINAS AGRÍCOLAS}

Cássia Aparecida Pasqual - Eugenio Ávila Pedrozo

Portanto, concedem prazos de garantia menores para seus produtos. Já no caso das empresas de médio e pequeno porte, pelo fato de produzirem um número menor de produtos e em menor escala, utilizam menos capital de giro, concedendo prazo maior de garantia, o que diminui o grau de perecibilidade dos produtos.

Por sua vez, quando avaliadas as diferentes características da demanda, verificou-se que o giro de estoque é elevado, uma vez que a maior parte dos produtos fabricados pelas diferentes empresas é feita "contrapedido" do cliente. A partir da amplitude de vendas verificourse elevada tendência sazonal nos SKUs nas empresas de peque no porte, ao passo que as empresas de porte médio e grande, mesmo estando sujeitas à sazonalidade, conseguem encurtar a amplitude de vendas, sugerindo uma presença mais consistente de vendas no mercado e melhor planejamento na produção, acionado por vendas "contrapedido". O mesmo fato é também corroborado pela visibilidade da demanda, uma vez que a maior parte das vendas em todos os portes de empresas apresenta a modalidade "contrapedido" do cliente. O indicador prazo de entrega mostrou níveis de agilidade mais elevados nas empresas de pequeno porte, em particular, em razão de apresentarem um número de itens de produtos acabados menor e com processos produtivos mais simplificados. Também são auxiliadas por sua elevada amplitude de vendas, que permite aproveitem o período sazonal para antecipar a fabricação e montagem de peças para os equipamentos agrícolas. Verificourse pelo número de concorrentes diretos que para as grandes empresas os produtos de maior valor apresentam menor número de concorrentes diretos. O contrário ocorre com as empresas de pequeno porte, uma vez que, para os produtos de maior custo, o número de concorrentes é maior no setor. Tais fatos evidenciam, nas grandes empresas, a produção de produtos diferenciados, sem muitos similares no mercado.

Por fim, verificoutse que as características da operação, tais como o tempo de resposta, nas empresas de grande porte é elevado, em virtude da dependência de matérias-primas importadas; por sua vez, as empresas de menor porte, apesar da necessidade de matérias-primas importadas, apresentam maior agilidade em termos de suprimento e distribuição, proporcionando maior rapidez na entrega do produto ao cliente. O grau de complexidade no fornecimento evidenciou, por um lado, que as grandes empresas apresentam processos produtivos complexos e de valores monetários altos para a fabricação de seus produtos; por outro, as empresas de porte médio e pequeno apresentam processos de produção mais simples, o que as torna mais ágeis. A razão entre prazos mostrou uma relativa similaridade entre as empresas de pequeno e de grande porte.

Concluise, com base nos resultados gerados a partir das características do negócio, que a principal implicação gerencial deste trabalho é a possibilidade de orientar e direcionar o planeja mento e 


\section{ARTIGOS - CARACTERÍSTICAS DO NEGÓCIO NO SETOR DE MÁQUINAS AGRÍCOLAS \\ Cássia Aparecida Pasqual - Eugenio Ávila Pedrozo}

a tomada de decisão. Para tanto, devem-se identificar as características das empresas em termos de porte, que parece constituir a variável mais decisiva. No setor de máquinas e implementos agrícolas não existe um padrão homogêneo de características do negócio capaz de explicar as decisões logísticas tomadas pelos gestores. Sugere-se, assim, a necessidade de segmentar uma eventual estratégia logística baseada nas características do negócio significativas nos diferentes portes, conforme definidas no presente trabalho.

Cabe salientar, finalmente, que os resultados das características do negócio no setor de máquinas e implementos agrícolas da presente pesquisa representam um avanço em posicionamento logístico (Wanke, 2000, 2003a e 2003b), em dois sentidos: primeiro, quanto à aplicação, pois concentrou-se em apenas um setor com um número maior de casos estudados; e, segundo, levou-se em conta o tamanho das organizações estudadas (pequenas, médias e grandes), verificando-se a importância de ser considerado este aspecto nas decisões sobre posicionamento logístico, obtendo-se maior agilidade e satisfação ao cliente. Nesse sentido, poderia ainda ser feita uma análise de correlação na qual se avalie a magnitude ou ordem de grandeza das diferentes características do negócio que podem influenciar as decisões logísticas e a organização do fluxo de produtos nas pequenas, médias e grandes empresas. Essas análises poderiam também ser realizadas em outros setores. Os resultados também poderiam ser utilizados como apoio para a tomada de decisão em políticas públicas, por tratarse de um aglomerado industrial fundamental para a região estudada e importante para o Brasil. Afinal é um dos setores brasileiros, ligados ao agronegócio, em que se trabalha com maior valor agregado, sendo importante tanto no mercado interno como externo.

\section{REFERÊNCIAS}

BNDES - Banco Nacional de Desenvolvimento Econômico e Social. Linha de financiamento. Disponível em <http://www.bndes.gov.br>. Acessado em maio 2004.

CHRISTOPHER, M. The agile supply chain: competing in volatile markets. Industrial Marketing Management, v. 29, s. n., p. 37-44, 2000.

COPPEAD - Centro de Estudos em Logística . UFRJ. Disponível em <http://www.cel.coppead.ufrj.br>. Acessado em mar. 2004. 


\section{ARTIGOS - CARACTERÍSTICAS DO NEGÓCIO NO SETOR DE MÁQUINAS AGRÍCOLAS \\ Cássia Aparecida Pasqual - Eugenio Ávila Pedrozo}

FINAMORE, E. B.; MONTOYA, M. A. PIB, tributos, emprego, salários e saldo comercial no agronegócio gaúcho. Ensaios, v. 24, n. 1, p. 93-126, 2003.

IBGE - Instituto Brasileiro de Geografia e Estatística. 2004. Disponível em <http://www.ib ge.gov.br/cartografia/mapeamento das unidades territoriais $>$. Acessado em maio 2004.

PASQUAL, C. A. Características do negócio como determinantes do posicionamento logístico no setor de máquinas e implementos agrícolas da mesorregião Noroeste Riograndense. 2005. Dissertação (Mestrado em Agronegócios). Centro de Estudos e Pesquisa em Agronegócios. Porto Alegre: Universidade Federal do Rio Grande do Sul, 2005.

PORTER, M. E. Towards a dynamic theory of strategy. Strategic Management Journal, v. 12, Special Issue, p.95-117, summer, 1991.

SIMERS - Sindicato de Máquinas Agrícolas do Estado do Rio Grande do Sul. Disponível em <http://www.simers.com.br>. Acessado em abr. 2004.

WANKE, P. F. Logística e gerenciamento da cadeia de suprimento: estratégias para redução de custos e melhoria dos serviços. São Paulo: Pioneira. 2002.

WANKE, P. F. O impacto das características do negócio nas decisões logísticas e na organização do fluxo de produtos: um estudo exploratório em seis setores econômicos. Revista de Administração Contemporânea, v. 7, n. 3, p. 163-180, 2003 a.

WANKE, P. F. Organização do fluxo de produtos como base da estratégia logística de produtos acabados: uma síntese dos enfoques estático e dinâmico. 2003. Tese (Doutorado em Engenharia de Produção). Rio de Janeiro: Universidade Federal do Rio de Janeiro, COPPEAD/UFRJ, 2003b. p. 340. 


\section{ARTIGOS - CARACTERÍSTICAS DO NEGÓCIO NO SETOR DE MÁQUINAS AGRÍCOLAS}

Cássia Aparecida Pasqual - Eugenio Ávila Pedrozo

\section{Artigo recebido em 24.11.2005. Aprovado em 10.11.2006.}

\section{Cássia Aparecida Pasqual}

Professora e coordenadora de do curso de Administração Rural e Agroindustrial na Universidade Estadual do Rio Grande do Sul - UERGS. Professora de Sistemas de Produção na Universidade de Passo Fundo - UPF. Mestre em Agronegócios no Programa de Pós-Graduação em Administração pela Universidade Federal do Rio Grande do Sul- UFRGS.

Interesses de pesquisas nas áreas de sistemas de produção, logística, gerenciamento de cadeias de suprimento, gerenciamento de unidades de produção, agronegócio.

E-mail: cpasqual@upf.br e cassia-pasqual@uergs.edu.br

Endereço: Rua XV de Novembro, 53, Bairro Vergueiro, Passo Fundo - RS, 99010-040.

\section{Eugenio Ávila Pedrozo:}

Professor do PPG-Agronegócios/Centro de Estudos e Pesquisas em Agronegócios - CEPAN na Universidade Federal do Rio Grande do Sul - UFRGS. Professor do PPGA/Escola de Administração na Universidade Federal do Rio Grande do Sul - UFRGS. Doutor em Doctorat em Gestion, no Institut National Polytechnique de Lorraine, França.

Interesses de pesquisas nas áreas de estratégia, cooperativismo, agronegócios, inovação tecnológica, sustentabilidade.

E-mail: eapedrozo@ea.ufrgs.br

Endereço: Av. João Pessoa, 31, Centro, Porto Alegre - RS, 90040-000. 